\title{
Developmental pathways that generate natural-killer-cell diversity in mice and humans
}

\author{
Nicholas D. Huntington, Christian A. J. Vosshenrich and James P. Di Santo
}

\begin{abstract}
Natural killer (NK) cells are large granular lymphocytes capable of producing inflammatory cytokines and spontaneously killing malignant, infected or 'stressed' cells. These NK-cell functions are controlled by cell-surface receptors that titrate stimulatory and inhibitory signals. However, we remain puzzled about where and when NK cells develop and differentiate, and this has fuelled the debate over the diversification of the peripheral NK-cell pool: are NK cells functionally homogeneous or are there subsets with specialized effector functions? In this Review, we consider the developmental relationships and biological significance of the diverse NK-cell subsets in mice and humans, and discuss how new humanized mouse models may help to characterize them further.
\end{abstract}

Cytokines and Lymphoid Development Unit and Inserm Unit 668, Institut Pasteur, 25 Rue du Docteur Roux, 75724 Paris, Cedex 15, France.

Correspondence to J.P.D. e-mail:disanto@pasteur.fr doi:10.1038/nri2154
Natural killer (NK) cells are a subset of lymphocytes that principally participate in innate immunity but may also have important roles in determining the outcome of the adaptive immune responses. Diverse functional activities have been associated with NK cells, including 'natural' (immediate) cytotoxicity and the capacity to promptly produce cytokines (tumour-necrosis factor (TNF) and interferon- $\gamma$ $(\mathrm{IFN} \gamma))$ and chemokines that help to generate and sustain an inflammatory environment (reviewed in REF. 1). By virtue of these different effector functions, NK cells are poised to participate in an early defence system that can directly eliminate virally infected or transformed cells through target-cell lysis, and/or recruit nonspecific haematopoietic cells (neutrophils and macrophages), activate dendritic cells (DCs) and prime adaptive lymphocytes ( $\mathrm{T}$ cells and $B$ cells) through the release of soluble amplifying factors. Understanding how NK cells develop into functional effector cells that are equipped with the potential to accomplish distinct roles in immunity remains a challenge, but it will be important to harness the therapeutic potential of these innate lymphocytes ${ }^{2}$.

The functional pleiotropy exhibited by NK cells provides the immune system with a 'multitasking' cell that could serve different biological roles under different conditions. Maintaining this property of NK cells would appear advantageous to the organism; however, programming NK cells (at the level of gene transcription) so that they are capable of a 'one cell does all' endpoint but that at the same time are still able to generate adequate effector functions under diverse assaults might prove difficult. So, rather than by having a single multifunctional cell, diverse NK-cell effector functions could be achieved in an alternative way through NK-cell diversification. In this way, the functional pleiotropy exhibited by NK cells during immune responses would be governed by distinct NK-cell subsets. Over the years, several reports have suggested that there are NK-cell subsets with specialized functions in humans and mice (including 'helper' NK cells with type 1 and 2 cytokine profiles, regulatory NK cells, cytotoxic NK cells and antigen-presenting $\mathrm{NK}$ cells ${ }^{3-5}$ ).

This notion of NK-cell diversity raises several fundamental questions, the most obvious being the definition of what constitutes an NK-cell subset in the first place. But once defined, it is important to know how and when NK-cell subsets arise. Do NK cells develop and differentiate in multiple sites? Does the site of NK-cell differentiation impart particular characteristics to the NK cells that develop there, resulting in the generation of NK-cell subsets? If NK-cell subsets exist, are their phenotypes and functions stable? What distinction needs to be made between activation and resting states for NK cells? Finally, is there a biological necessity for NK-cell diversity? In this Review, we examine the evidence for functional NK-cell subsets in mice and humans. 


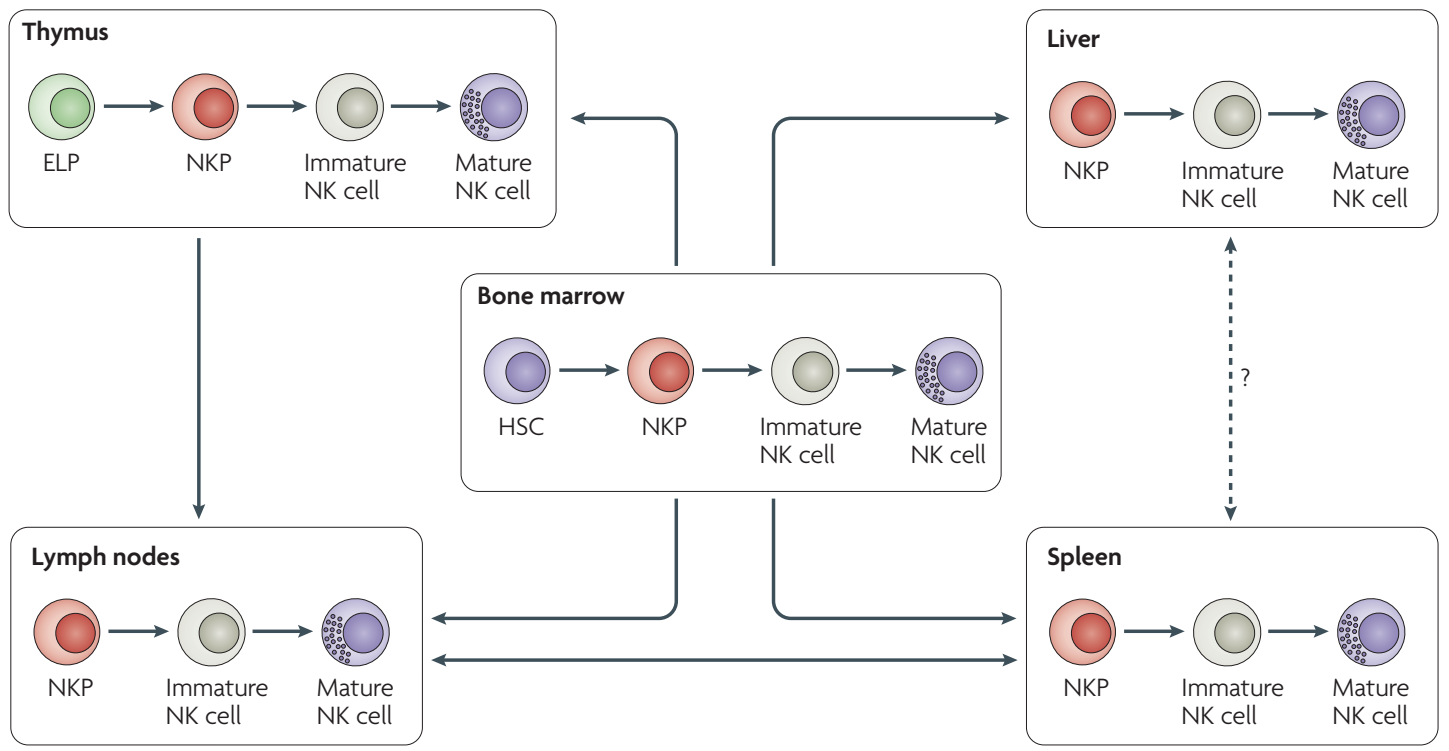

Figure 1 | Multiple sites for NK-cell development. For an individual tissue site, one can distinguish committed natural killer (NK)-cell precursors (NKPs); in the bone marrow and thymus these differentiate from haematopoietic stem cells (HSCs) or early lymphoid precursors (ELPs). Immature NK cells provide the substrate for the process of NK-cell education, which results in mature NK cells with functional competence. Mature NK cells may also be considered according to their activation state (resting or activated, for example; not shown). NKPs, immature NK cells and mature NK cells may recirculate between different tissue sites (bone marrow, thymus, liver, spleen and lymph nodes).

\section{States and sites of NK-cell differentiation}

Prior to describing the phenotype and functional attributes of immature NK cells and their differentiated progeny, some generalities of NK-cell development should be considered (FIG. 1). For any given tissue localization, we can distinguish 'stages' in the life of an NK cell. Multiple factors condition this process, including cell-intrinsic signals (transcription factors; for a recent review, see REF. 6) and environmental cues. The first stage is defined by the NK-cell precursor (NKP) that is generated from multipotent haematopoietic precursors (including haematopoietic stem cells (HSCs) and early lymphoid precursors (ELPs)). By definition, NKPs have the potential to develop into mature NK cells but not into any other haematopoietic lineage. NKPs give rise to immature NK cells, which express some (but not all) NK-cell-specific markers; immature NK cells are considered to be the precursors to more mature NK cells. Whether immature NK cells have functional roles in immunity is not clear, although some studies have shown that NK cells with an immature phenotype have functional attributes (for examples, see REF. 6).

As immature NK cells differentiate further, NK-cell receptors specific for MHC class I molecules are expressed in a stochastic, variegated and overlapping manner ${ }^{7}$, and are tested in a process that has been referred to as 'NK-cell education'. NK-cell education results in two types of mature NK cell: the type that expresses at least one inhibitory NK-cell receptor that has been engaged by self MHC molecules present in the environment in which the education occured, and the type that expresses self-specific NK-cell receptors that have not been engaged by self MHC molecules. Recent studies have shown that the engagement of inhibitory NK-cell receptors by MHC ligands is critical to allow developing NK cells to achieve their full functional competence $e^{8-11}$. Yokoyama and colleagues refer to this education process as 'licensing" ${ }^{12}$, whereas Raulet and colleagues favour a 'disarming' model ${ }^{13}$. While the terminology debate rages, the precise molecular mechanism by which education occurs remains unknown. Educated or licensed NK cells have a mature phenotype, are fully responsive to triggering by activating receptors and are tolerant to self. Mature NK cells that develop in the absence of interactions with self MHC molecules are 'hyporesponsive' to activation signals.

All NK cells may leave the site of their generation and take up residence in other tissues (such as the secondary lymphoid organs, lungs, liver and gut). In these peripheral sites, mature NK cells can be further distinguished by their activation state: 'resting' NK cells are mostly a default definition (lacking signs of recent activation), whereas 'activated' NK cells are larger in size, bear markers of recent stimulation (such as CD69) and can demonstrate heightened functional properties. It is also possible that chronically stimulated NK cells that are analogous to 'exhausted' $\mathrm{T}$ cells exist ${ }^{14}$. The complex process of NK-cell differentiation occurs at several distinct tissue sites, including the bone marrow, liver, thymus, spleen and lymph nodes, and may involve the circulation of NK cells at different stages of maturation between these sites (FIG. 1). The comparison of human and mouse molecules expressed by NKPs, immature NK cells and mature NK cells reveals a remarkable conservation of phenotypes and functions (FIG. 2), although there 
Fetal thymic organ cultures (FTOCS). Removal of fetal thymi between embryonic day 14 and 16 allows the analysis of several key processes in thymic development, including antigen-driven positive- and negative-selection events, using in vitro culture. The thymic lobes can also be used to support the development of progenitor cells that are added to the cultures.

\section{NKT cells}

(Natural killer T cells). A subpopulation of T cells that expresses NK-cell markers. In the C57BL/6 mouse strain, NKT cells express CD 161 (NKRP1C) and the T-cell receptor (TCR). Some NKT cells recognize $C D 1 d-$ associated lipid antigens and express a restricted repertoire of TCRs. After TCR stimulation of naive mice, NKT cells rapidly produce interleukin-4 and interferon- $\gamma$.

$\gamma \delta \mathrm{T}$ cells

$\mathrm{T}$ cells that express the $\gamma \delta \mathrm{T}$-cell receptor. These T cells are present in the skin, vagina and intestinal epithelium as intraepithelial lymphocytes

(IELs). Although the exact function of $\gamma \delta \mathrm{T}$ cells is unknown, it has been suggested that mucosal $\gamma \delta \mathrm{T}$ cells are involved in innate immune responses.

YAC-1 cells

A mouse lymphoma cell line that was established by inoculation of the Moloney leukaemia virus (MLV) into a newborn A/Sn mouse. YAC-1 cells are sensitive to lysis by murine natural killer (NK) cells and are therefore used as target cells in assessing NK-cell cytotoxicty. are some differences in the expression pattern of certain receptors (for example, Ly49 expression in mice versus KIR (killer-cell immunoglobulin-like receptor) expression in humans or lack of CD56 expression in mice).

NK-cell precursors in the bone marrow. The bone marrow has been considered the main site for NK-cell development, as ablation of the bone-marrow microenvironment was associated with dramatic defects in NK-cell homeostasis and function ${ }^{15,16}$. Several (and perhaps all) aspects of NK-cell development can occur in the bone marrow, including the generation of NKPs from haematopoietic precursors, the acquisition of expression of the NK-cell surface receptors involved in target-cell recognition, NK-cell education, and the emergence of differentiated NK cells with full functional competence (reviewed in REFS 17-19). By analysing immature and mature NK cells in the bone marrow, models have emerged proposing several distinct stages for developing NK cells (reviewed in REF. 18).

NKPs in mice were initially identified in the asialo-GM1- bone-marrow fraction, although this cell population was not homogeneous as it could still give rise to both myeloid cells and other lymphocytes ${ }^{20}$. Although more lymphoid-restricted bone-marrow subsets that have NK-cell potential have been recently characterized $^{21}$, none of these represent true NKPs, as all can differentiate into $\mathrm{CD} 19^{+} \mathrm{B}$ cells and can colonize or reconstitute the thymic population. The only NK-cell-restricted murine bone-marrow subset that has been described to date is a lineage (LIN) ${ }^{-} \mathrm{CD} 49 \mathrm{~b}^{-}$ $\mathrm{CD} 161^{-} \mathrm{CD} 122^{+}$population that can differentiate into mature NK cells in vitro or in fetal thymic organ cultures (FTOCs) ${ }^{22}$. Although enriched in NKPs (about 1 in 10 cells gives rise to a NK cell in vitro), this population is still heterogeneous for the expression of natural-killer group 2, member D (NKG2D), suggesting that true NKPs might be NKG2D positive ${ }^{22,23}$.

In humans, bone-marrow NKPs have been identified that give rise to $\mathrm{CD} 3^{-} \mathrm{CD} 56^{+} \mathrm{NK}$ cells following in vitro culture with soluble factors (including interleukin-2 (IL-2) or IL-15). Human NKPs form part of the $\mathrm{CD} 34^{+} \mathrm{CD} 38^{+} \mathrm{CD} 45 \mathrm{RA}^{+}$subset $^{24-27}$, and further selection for $\mathrm{CD}^{+}$cells enriches for NKPs that express transcripts of CD122 (REFS 28,29). A more differentiated $\mathrm{CD}^{+} \mathrm{CD} 34^{-} \mathrm{LIN}^{-}$subset also generates functional NK cells in vitro and may represent a more restricted NKP population ${ }^{30}$. So, in both mice and humans, there are bone-marrow cells with the functional properties of NKPs (FIG. 2), and these provide a starting point for understanding the transcriptional regulation that takes place during commitment to the NK-cell lineage.

Immature NK cells. Unlike NKPs, mouse immature NK cells express CD161 (a family of C-type lectin receptors that includes NKRP1C (also known as CD161c), which is recognized by NK1.1 antibodies in $\mathrm{C} 57 \mathrm{BL} / 6$ and C57BL/10 mouse strains). Although CD161 (NKRP1C) is expressed by all immature and mature NK cells in C57BL/6 mice, it is not an NK-cell-specific marker as it can also be detected on NKT cells and some $\gamma \delta$ T cells. A family of natural cytotoxicity receptors (NCRs), including NKp30 (NK-cell protein 30), NKp44 and NKp46 (also known as NRC1), that are expressed in an NK-cell-specific manner (reviewed in REF. 31) has been described in humans. NKp46 is highly expressed in NK cells, and mice that express green fluorescent protein (GFP) reporter genes under the control of NKp46 regulatory sequences show an NK-cell-specific transcription programme that starts at the immature NK-cell stage in the bone marrow ${ }^{32,33}$ (J.P.D. and O. Mandelboim, unpublished observations). By contrast, immature NK cells express neither CD49b (also known as $\alpha_{2}$-integrin; which is recognized by the monoclonal antibody DX5) nor CD43 and only low levels of CD11b (also known as $\alpha_{\mathrm{M}}$-integrin) and CD11c (also known as $\alpha_{x}$-integrin). Immature NK cells begin to express CD94 and a few express the Ly49 receptor ${ }^{22,34}$ (C.A.J.V. and J.P.D., unpublished observations). The adoptive transfer of immature NK cells in vivo results in the generation of Ly $49^{+} \mathrm{NK}$ cells, indicating that immature NK cells are the precursors of more mature NK cells ${ }^{35}$. Immature NK cells are not cytotoxic towards YAC-1 cell targets (an NK-cell-sensitive murine thymoma cell line) in vitro and fail to secrete IFN $\gamma^{22}$.

In humans, antibodies specific for CD161 (NKRP1A) have also proved useful in characterizing immature NK cells. A population of $\mathrm{CD}^{-} \mathrm{CD} 56^{-} \mathrm{CD} 161^{+}$cells has been detected in umbilical cord blood, and these cells can be generated in vitro from $\mathrm{CD}_{3} 4^{+} \mathrm{LIN}^{-}$cord blood cells, suggesting that initial expression of CD161 identifies human immature $\mathrm{NK}$ cells ${ }^{36-39}$. These cells lack expression of KIR-family proteins and NKp46 (REFS 27,37). In addition, these $\mathrm{CD}^{-} \mathrm{CD} 56^{-} \mathrm{CD} 161^{+}$ cells are poorly cytolytic compared with the more mature $\mathrm{CD} 56^{+} \mathrm{CD} 161^{+}$cells, but they can acquire CD56 expression and high levels of natural cytotoxicity after in vitro culture $\mathrm{e}^{37,39}$. Interestingly, CD $56^{-} \mathrm{CD} 161^{+}$cells were able to mediate cytotoxicity through TNF-related apoptosis-inducing ligand (TRAIL), but this was not the case for the more mature $\mathrm{CD} 56^{+} \mathrm{CD} 161^{+} \mathrm{NK}$ cells ${ }^{39}$. Although TRAIL-dependent cytotoxicity has not been described for mouse immature NK cells in the bone marrow, these cells express TRAIL ex vivo (C.A.J.V. and J.P.D., unpublished observations). Collectively, the available data argue convincingly for the existence of immature NK cells in the bone marrow of mice and humans that represent an intermediate stage in NK-cell development towards maturity (FIG. 2).

Are NKPs and immature NK cells unique to the bone marrow? The available data from mice studies suggest that this is not the case as immature NK cells have been found at other sites, including a prominent population in the peri-natal liver (BOX 1), and a small but discernible population in the spleen ${ }^{23,40}$. Human NKPs are also found in the lymph nodes ${ }^{27,41}$. These observations are consistent with the idea that multiple sites can support NK-cell differentiation. Alternatively, it suggests that once generated in the bone marrow, NKPs and immature NK cells might have access to the circulation. 


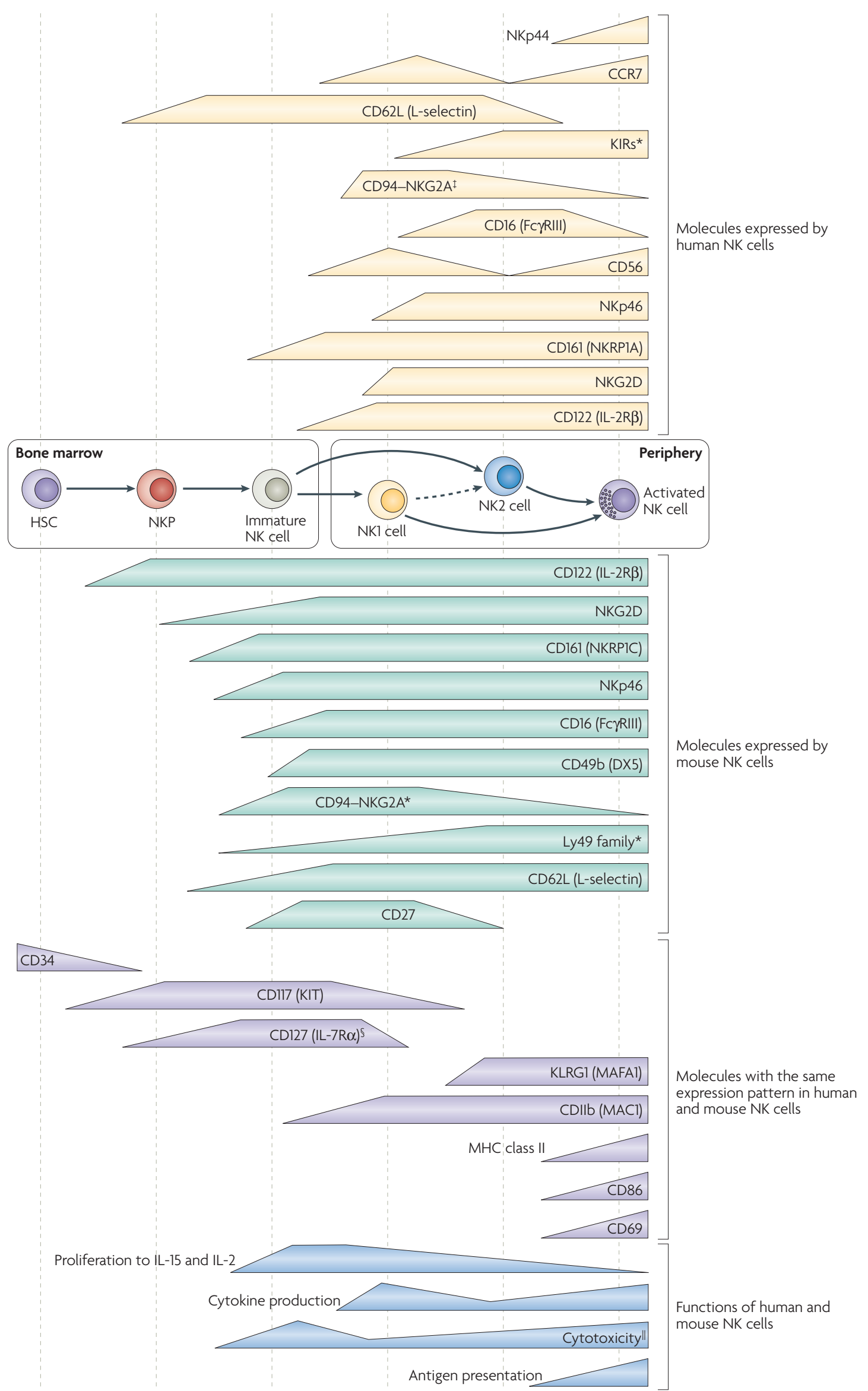




\section{Figure 2 | Phenotypic and functional characteristics of human and mouse}

NK cells. The traditional view of natural killer (NK)-cell development is represented by a linear pathway from haematopoetic stem cells (HSCs) in the bone marrow to fully functional NK cells in the periphery. This diagram depicts the expression pattern of several molecular markers in humans and mice throughout the stages of NK-cell maturation. NK-cell precursors (NKPs) lack typical NK-cell markers but give rise to NK cells. Immature NK cells express CD161 and natural-killer group 2, member D (NKG2D) in both mice and humans, as well as receptors required for growth and survival. NK-cell education via self MHC class I molecules probably begins at the immature NK-cell stage. More mature NK cells leave the bone marrow and populate peripheral lymphoid organs (spleen, liver and lymph nodes). Peripheral NK cells can be activated following detection of missing or altered self MHC class I molecules or by an inflammatory environment. Activated NK cells have increased functional capacity compared to resting NK cells. Peripheral NK-cell subsets (NK1 and NK2 cells) have also been proposed in mice and humans. Some phenotypic and functional properties of the NK2-cell subsets differ from the NK1-cell subset; for example, human NK2 cells are $\mathrm{CD} 56^{\text {low }} \mathrm{CCR}^{-}$, whereas human NK1 cells are $\mathrm{CD} 56^{\text {hi }} \mathrm{CCR} 7^{+}$. Although most evidence suggests that NK2 cells arise from NK1 cells, it is also possible that they both arise from a common precursor (an immature NK cell). *Heterogeneous expression. ${ }^{\ddagger}$ Heterogeneous expression in NK2 cells. ${ }^{\circledR}$ Thymus derived NK cells in mice. "Tumournecrosis-factor-related apoptosis-inducing ligand (TRAIL)-mediated cytotoxicity is more prominent in neonatal mice. CCR7, CC-chemokine receptor 7; CD62L, CD62 ligand; IL, interleukin; KIR, killer-cell immunoglobulin-like receptor; KLRG1, killer-cell lectin-like receptor subfamily G, member 1; NKp46, NK-cell protein 46.

NK-cell education: linking functional competence and maturation. The process of education generates NK cells that are tolerant to self and have the capacity to 'sense' MHC class I expression levels on target cells that may vary during infection, transformation or stress (reviewed in REF. 13). Several reports have provided evidence that self MHC interactions are important for human or mouse NK cells to attain full functional competence ${ }^{8-11}$. However, the stage at which this process occurs in the bone marrow (or at other sites) has not yet been defined. In the periphery, both educated NK cells (inhibitory NK-cell receptors engaged by self MHC molecules) and hyporesponsive NK cells (no engagement by self MHC molecules) have a mature phenotype $\left(\mathrm{CD} 11 \mathrm{~b}^{\text {hi }} \mathrm{CD} 49 \mathrm{~b}^{+}\right)^{10}$. As the expression of NK-cell receptors specific for self MHC are first detected on immature NK cells ${ }^{22}$, it is plausible that education is initiated at this stage and, when completed, results in mature CD49b ${ }^{+} \mathrm{NK}$ cells that are either educated or hyporesponsive. Alternatively, immature NK cells might not be competent for the educational process, either owing to intrinsic or environmental constraints, so that only more mature NK cells (expressing $\mathrm{CD} 49 \mathrm{~b}$ ) would be educated. Whatever the stage, triggering of NK-cell receptors specific for self MHC would transmit a (yet ill-defined) signal to the maturing cells and represent a quality control checkpoint in the differentiation process. Self $\mathrm{MHC}$ recognition can activate an ITIM (immunoreceptor tyrosine-based inhibitory motif)-dependent phosphatase reaction within NK cells, and although this pathway may be involved in NK-cell education, the precise protein targets involved are not known. Last, the cell type that provides the self MHC signal (and potentially other essential membrane or soluble factors) is likewise undefined.

Although most developing NK cells become educated, around $10-20 \%$ of human or mouse NK cells do not express any known inhibitory receptors for self MHC class I molecules ${ }^{8-10}$. These cells would be potentially harmful as they would not be subject to inhibition by self MHC class I molecules. One curious property of these NK cells is their reduced response to stimulation via activating receptors. This hyporesponsiveness could explain how these NK cells fail to provoke pathology under normal circumstances. Despite their functional differences, hyporesponsive and educated NK cells have an almost indistinguishable cell-surface phenotype (including similar levels of NKp46, NKG2D, CD11b and CD16) and both express perforin and granzyme $B$ (in mice and humans). However, the presence of hyporesponsive NK cells poses questions about the efficiency of the educational

\section{Box 1 | Liver immature NK cells: a window of opportunity for NK-cell development?}

The presence of immature natural killer (NK) cells in the peri-natal mouse liver suggests that it is a site of NK-cell development, in addition to the bone marrow. These liver NK cells have an immature phenotype (CD $11 b^{\text {low }} C D 49 b$ Ly $\left.49^{-}\right)^{40,106}$. Although liver immature NK cells have little spontaneous cytotoxic activity against YAC-1 cell targets, they express TRAIL (tumour-necrosis-factor-related apoptosis-inducing ligand) and can eliminate TRAIL-sensitive targets in vitro and in vivo ${ }^{40,106}$. In this way, immature NK cells in the liver of newborn mice seem to be analogous to human immature NK cells in human cord blood, which can also kill their targets in a TRAIL-dependent manner ${ }^{39}$. Mouse TRAIL+ immature NK cells can develop into more mature TRAIL- Ly49+ NK cells following adoptive transfer in vivo ${ }^{40}$, a property that is reminiscent of the precursor capacity of human cord blood CD56-CD $161^{+} \mathrm{TRAIL}^{+}$immature $\mathrm{NK}$ cells, which generate mature CD $56^{+} \mathrm{CD} 161^{+} \mathrm{TRAIL}^{-} \mathrm{NK}$ cells when cultured in vitro ${ }^{39}$. TRAIL ${ }^{+}$immature NK cells are markedly reduced in the liver of adult mice compared with newborn mice, suggesting that NK-cell development in the liver is a transient phenomenon and coincides with the haematopoietic capacity of this organ during the peri-natal period.

NK cells also represent about half of the infiltrating lymphocytes in the human liver ${ }^{107,108}$. Interestingly, human liver NK cells have a CD56 low phenotype, but lack CD16 expression and therefore do not correspond to the typical mature circulating $\mathrm{CD} 16^{+} \mathrm{CD} 56^{\text {low }} \mathrm{NK}$ cells ${ }^{107-109}$. One clue to the biological role for $\mathrm{TRAIL}^{+} \mathrm{NK}$ cells is provided by studies of patients with chronic infection with hepatitis B virus. Infected hepatocytes express the TRAIL receptor and are susceptible to TRAIL-dependent apoptosis by CD56 ${ }^{\text {hiTRAIL }}+\mathrm{NK}$ cells, which are enriched in the liver of these patients ${ }^{110}$. TRAIL expression by human liver NK cells could be induced by interferon- $\alpha(\text { IFN } \alpha)^{110}$; by contrast, TRAIL expression by mouse liver NK cells seems to be under the control of IFN $\gamma$ (REF. 40). Based on these findings, one hypothesis is that TRAIL-dependent killing by NK cells could serve as an inducible defence mechanism that protects the organism from infection and/or cellular transformation. This mechanism could also be relevant during the activation of mature NK cells in response to immune stimulation. 


\section{Box 2 | IKDCs: a population containing activated NK cells?}

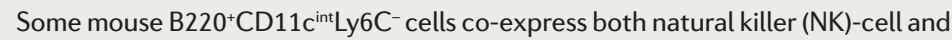
dendritic cell (DC) markers. These $\mathrm{B} 220^{+} \mathrm{CD} 11 \mathrm{c}^{\text {int }}$ cells are highly cytolytic, can be stimulated to produce both type I and type II interferons (IFNs) and can present peptides to antigenic-specific T-cell clones. Based on these properties, this cell subset was named IFN-producing killer DCs (IKDCs) $)^{111,112}$.

So far, the function of IKDCs has been mostly assessed at the population level. It would appear important, however, to rigorously demonstrate that single cells behave similarly, as multifunctional IKDCs may simply reflect heterogeneity in the $\mathrm{B} 220^{+} \mathrm{CD} 11 \mathrm{C}^{\text {int }}$ Ly6 $\mathrm{C}^{-}$cell pool. IKDCs were originally distinguished from NK cells by their higher level of expression of B220 and CD11c. However, B220 expression is not bimodal on peripheral NK cells and therefore the comparison of $\mathrm{B} 220^{+}$IKDCs with B220- NK cells is arbitrary. Other than IFN $\alpha$ production (which might be explained by contamination of IKDCs with plasmacytoid DCs ${ }^{111,113}$ ), the functional activities of IKDCs and NK cells in mice are quite similar (TABLE 1).

What then distinguishes IKDCs from NK cells? One report indicated that IKDCs develop independently of the common cytokine-receptor $\gamma$-chain $\left(\gamma_{c}\right)$, whereas conventional NK cells are completely absent in these mice ${ }^{111,113}$. Curiously, CD122 (the interleukin-2 receptor $\beta$-chain) was required for IKDC development ${ }^{112}$. Although a dependence on CD122 expression would be consistent with the known ability of interleukin-2 to synergize with imatinib mesylate to enhance TRAIL-mediated cytotoxicity by IKDCs ${ }^{111}$, it is not clear how a CD122-dependent, yet $\gamma_{c}$-independent, cell would be generated (as all known CD122-dependent ligands are also $\gamma_{c}$ dependent).

A second distinguishing feature of IKDCs is their capacity to present (but not process) antigen, which is probably related to their high level of expression of MHC class II molecules ${ }^{112}$. Most resting mouse NK cells lack expression of MHC class II molecules ${ }^{112}$, although these molecules can be induced after activation in vitro and in vivo (C.A.J.V. and J.P.D., unpublished observations). Similarly, most resting human NK cells are HLA-DR negative, although inducible expression was observed in vitro in a mixed-lymphocyte reaction ${ }^{114}$ and is seen in activated human NK cells isolated from the tonsils following chronic inflammation or from the decidual tissue of pregnant women infected with cytomegalovirus ${ }^{115}$. HLA-DR+ human NK cells have a large granular morphology, express increased levels of CD86, CD80 and CD70 molecules, as well as MHC class II molecules, are highly cytotoxic, and, similar to their murine equivalents, can present antigen to $\mathrm{CD} 4^{+} \mathrm{T}$ cells ${ }^{114,115}$. So, increased MHC class II expression appears to characterize activated human and mouse NK cells that have enhanced functional capabilities. Should IKDCs be considered a distinct cell subset? Based on the available evidence, we propose that $\mathrm{B} 220^{+} \mathrm{CD} 11 \mathrm{c}^{\text {int }} \mathrm{Ly} 6 \mathrm{C}^{-}$cells (IKDCs) in mice are simply activated NK cells.

Common cytokine-receptor $\gamma$-chain

$(\gamma)$. A shared cytokine receptor

chain for a group of shortchained, four-helical bundle

interleukins, including interleukin-2 (IL-2), IL-4, IL-7, IL-9, IL-15 and IL-21

Imatinib mesylate

A tyrosine kinase inhibitor that

is currently used in treating

malignancies, including chronic

myelogenous leukaemia and

gastrointestinal stromal

tumours. Imatinib mesylate

interacts with the ATP binding site of the fusion protein BCR-

ABL (Abelson leukaemia-virus protein $(A B L)$ fused with the

breakpoint-cluster region $(\mathrm{BCR}))$, blocking the activity

of this protein, which is

constitutively active in certain

forms of cancer procedure, which may be inadequate to assure that all NK cells are educated. Hyporesponsive mouse NK cells secreted the same amount of IFN $\gamma$ in response to infection in vivo when compared to educated NK cells, and hyporesponsive NK-cell function could be corrected by culture with IL-2 in vitro ${ }^{10}$. So, hyporesponsive NK cells may have biological roles and utility beyond 'missingself-MHC' recognition. Interactions between C-type lectin-related ligands and stimulatory or inhibitory NKPR1 receptors ${ }^{42,43}$ might parallel or complement the process of education and help to explain the development of functional competence by hyporesponsive NK cells in the absence of classical MHC molecules. Defining the stage at which these different receptors are triggered might shed light on the mechanisms underlying the educational process. Finally, functions that do not involve receptors for self MHC class I molecules and instead involve the detection of viral or microbial infections might be independent of the process of education, although the acquisition of self-MHC-receptor-independent functions might require an equivalent educational process. So, development of complete functional capacities by NK cells might necessitate an ensemble of educational processes.
Mature NK cells: further complexities in phenotype and function. NK cells that have completed their education and attained full functional competence leave their generation site to take up residence in the periphery. In mice, the main peripheral sites where mature NK cells are found include the spleen, liver, lungs and blood and, to a lesser extent, the bone marrow, lymph nodes and thymus. Mature NK cells in mice express CD49b, CD122, CD161, NKG2D, NKp46 and a range of Ly49 receptors, as well as high levels of CD11b and CD43. These NK cells lyse YAC-1 targets and produce cytokines (IFN $\gamma$ and TNF) after stimulation with target cells or exposure to a combination of IL-12 and IL-18 (reviewed in REF. 18). Although these observations suggest that most mature NK cells are homogeneous, other evidence points to the contrary. For example, only a fraction of splenic NK cells expresses IFN $\gamma$ after stimulation, and analysis of CD107a expression (as a marker of granule exocytosis) suggests that only a subset of NK cells are involved in natural cytotoxicity ${ }^{44}$. So it is likely that the mature NK-cell pool in mice is composed of NK-cell subsets with different functional properties.

Hayakawa and Smyth identified CD27 as a new marker that subdivides the NK-cell pool in mice ${ }^{45}$. On the basis of $\mathrm{CD} 27$ and $\mathrm{CD} 11 \mathrm{~b}$ expression, these authors characterized three NK-cell subsets and proposed a linear differentiation model of $\mathrm{CD} 11 \mathrm{~b}^{\text {low }} \mathrm{CD} 27^{+}$to $\mathrm{CD}_{11 \mathrm{~b}}{ }^{\text {hi }} \mathrm{CD} 27^{+}$to $\mathrm{CD} 11 \mathrm{~b}^{\text {hi }} \mathrm{CD} 27^{-} \mathrm{NK}$ cells. This scheme is based on the early appearance of $\mathrm{CD} 11 \mathrm{~b}^{\text {low }} \mathrm{CD} 27^{+}$ NK cells after bone-marrow transplantation and the observation that purified $\mathrm{CD} 11 \mathrm{~b}^{\mathrm{low}} \mathrm{CD} 27^{+} \mathrm{NK}$ cells give rise to $\mathrm{CD} 11 \mathrm{~b}^{\text {hi }} \mathrm{CD} 27^{+} \mathrm{NK}$ cells after adoptive transfer ${ }^{45,46}$. Phenotypically, CD11 $b^{\text {low }} \mathrm{CD} 27^{+} \mathrm{NK}$ cells express higher levels of the CXC-chemokine receptor 3 (CXCR3) and slightly lower levels of Ly49 receptors, whereas the CD11 ${ }^{\mathrm{hi}} \mathrm{CD} 27^{-}$subset lacks CXCR3 expression but expresses more Ly49 receptors. The $\mathrm{CD} 11 \mathrm{~b}^{\text {hi }} \mathrm{CD} 27^{-}$ subset has increased expression of KLRG1 (killer-cell lectin-like receptor subfamily G, member 1), an inhibitory receptor that is induced after chronic stimulation and proliferation ${ }^{47}$. Functionally, $\mathrm{CD} 11 \mathrm{~b}^{\text {low }} \mathrm{CD} 27^{+} \mathrm{NK}$ cells are potent cytokine producers but are less cytotoxic than the intermediate $\mathrm{CD} 11 \mathrm{~b}^{\mathrm{hi}} \mathrm{CD} 27^{+}$subset, and both of these subsets are more functional than $\mathrm{CD} 11 \mathrm{~b}^{\text {hi }} \mathrm{CD} 27^{-} \mathrm{NK}$ cells. Interestingly, CD $11 b^{\text {low }} \mathrm{CD} 27^{+}$ NK cells are prevalent in the lymph nodes and bone marrow, whereas the $\mathrm{CD} 11 \mathrm{~b}^{\mathrm{hi}} \mathrm{CD} 27^{-} \mathrm{NK}$ cells are enriched in the blood, spleen and lungs. Collectively, these results provide strong evidence for an activation-induced differentiation of peripheral NK cells in mice, which modifies their functional capacities (FIG. 2). However, whether subsets defined by the CD27 marker represent developmentally distinct NK-cell subsets has not been clearly demonstrated. As the recently described IFN-producing killer DC (IKDC) subset has similarities to activated NK cells (BOX 2, TABLE 1), it would be interesting to investigate whether the expression of MHC class II molecules and co-stimulatory receptors (CD80 and CD86) are enriched in the CD11 b ${ }^{\text {hi }} \mathrm{CD} 27^{+}$NK-cell subset. 
Plasmacytoid DCs

A dendritic cell (DC) subset that morphologically resembles a plasmablast. Plasmacytoid DCs produce large amounts of type I interferons in response to viral infection
Mature human NK cells represent a substantial fraction of circulating lymphocytes in humans (up to 20\%), but they are typically less frequent in the spleen and bone marrow (5-10\%), and are uncommon in uninfected lymphatics $(<1 \%)^{1,48,49}$. Lanier and colleagues first proposed that human peripheral blood NK-cell subsets existed ${ }^{50}$, and subsequently an impressive collection of literature detailing the functional and phenotypic differences between mature human peripheral NK-cell subsets has been compiled (reviewed in REFS 51,52). Two human NK-cell subsets were defined by the differential cell-surface expression of CD16 (also known as Fc $\gamma$ RIII) and CD56 on circulating CD3- lymphocytes; $\mathrm{CD} 16^{+} \mathrm{CD} 56^{\text {low }} \mathrm{NK}$ cells represent $\sim 90 \%$ of NK cells in the blood, whereas the remainder are CD16-CD56 ${ }^{\text {hi }} \mathrm{NK}$ cells ${ }^{53}$. CD16-CD56 ${ }^{\text {hi }}$ NK cells express CD94-NKG2A, CCR7, CD25 and CD117 (also known as KIT) but lack expression of KIRs, whereas $\mathrm{CD} 16^{+} \mathrm{CD} 56^{\text {low }}$ NK cells are CD94-NKG2 $\mathrm{A}^{+/-} \mathrm{CCR}^{-} \mathrm{CD} 25^{-} \mathrm{CD} 62 \mathrm{~L}^{-}$ CD117- but express KIRs ${ }^{54-61}$. These two NK-cell subsets also show differential functions: CD16-CD56 $6^{\text {hi }} \mathrm{NK}$ cells produce greater amounts and a wider range of cytokines (IFN $\gamma$, TNF, granulocyte/macrophage colony-stimulating factor (GM-CSF), IL-13 and IL-10) than CD16 $6^{+} \mathrm{CD} 56^{\text {low }}$ NK cells ${ }^{54,62,63}$. By contrast, CD $16^{+} \mathrm{CD} 56^{\text {low }} \mathrm{NK}$ cells have abundant intracellular perforin and display enhanced cytotoxicity ${ }^{53,61,63}$. Whether these two NK-cell subsets in humans share a precursor-product relationship or are the result of independent pathways of development is not known. Recent molecular characterization of the thymic NK-cell developmental pathway in mice (see later) may provide a means to address the second issue.

Similar to mouse $\mathrm{CD} 27^{+} \mathrm{NK}$-cell subsets, human $\mathrm{CD}^{2} 6^{+} \mathrm{NK}$-cell subsets show some degree of plasticity, as cytokine activation can modify their phenotype and function. Cytokine stimulation downregulates CD16 expression and upregulates CD56 and CCR7 expression on $\mathrm{CD} 16^{+} \mathrm{CD} 56^{\text {low }} \mathrm{NK}$ cells in vitro ${ }^{64,65}$. Moreover, cytokines can greatly enhance cytotoxicity and cytokine production of $\mathrm{CD} 16^{-} \mathrm{CD} 56^{\mathrm{hi}}$ and $\mathrm{CD} 16^{+} \mathrm{CD} 56^{\text {low }} \mathrm{NK}$-cell subsets, respectively ${ }^{63-67}$. Whether repeated stimulation results in functional exhaustion in human NK cells has not yet been demonstrated, but could be relevant in the case of chronic infections and inflammation.

A new pathway of NK-cell development in the thymus. A new thymic pathway of NK-cell development has recently been characterized in mice ${ }^{68,69}$. Thymic NK cells were found to express high levels of CD127 (the IL-7

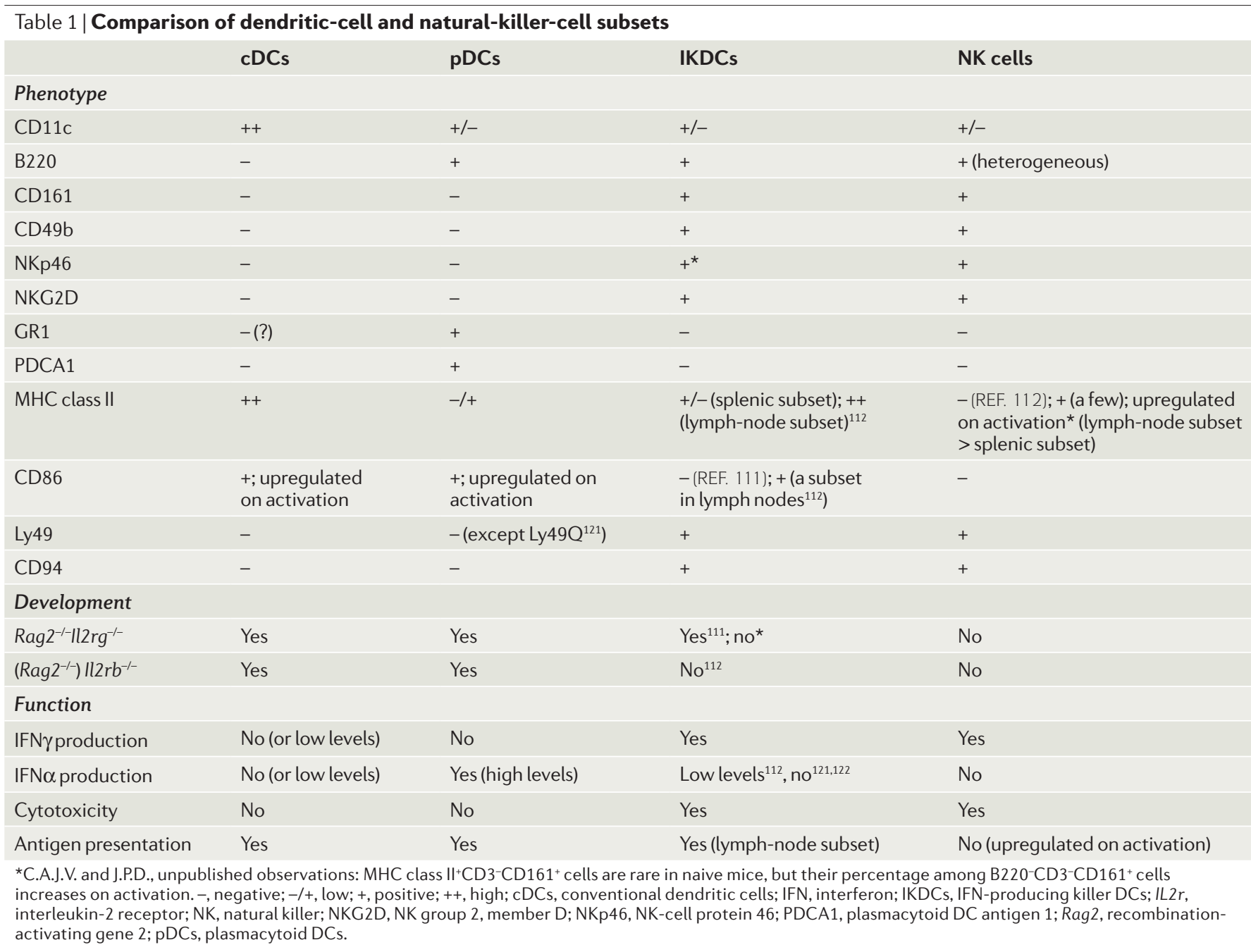


receptor $\alpha$-chain) and were functionally distinct from $\mathrm{CD}^{2} 27^{-} \mathrm{NK}$ cells from the spleen, blood and liver. Thymic $\mathrm{CD}_{127^{+}} \mathrm{NK}$ cells had a CD $11 \mathrm{~b}^{\text {low }} \mathrm{CD} 16^{-} \mathrm{CD} 69^{+} \mathrm{Ly} 49^{-}$phenotype and showed reduced lytic potential, but produced high amounts of IFN $\gamma$, TNF and GM-CSF when restimulated in vitro ${ }^{69}$. Interestingly, thymic $\mathrm{CD} 127^{+} \mathrm{NK}$ cells were exported to the lymph nodes, where they represented a substantial fraction of resident NK cells, and $\mathrm{CD} 127^{+} \mathrm{NK}$ cells were reduced in the lymph nodes of athymic mice ${ }^{69}$. These data suggest that haematopoietic precursor cells that seed the thymus generate NK cells by a different developmental programme than that used to generate NK cells in the bone marrow, although it remains possible that completely different precursors are the cellular substrates for NK-cell development at these two sites.

The zinc-finger transcription factor GATA3 was found to be essential for the development of thymic NK cells $^{69}$. Although GATA3 was previously shown to be redundant for bone-marrow-dependent NK-cell development, GATA3-deficient NK cells appeared less mature and produced less IFN $\gamma$ than wild-type cells, which is consistent with a general role for this transcription factor (among others ${ }^{18}$ ) in controlling NK-cell cytokine production. Although IL-7 deficiency has no effect on NK-cell development in the bone marrow, it abrogates thymic NK-cell development ${ }^{69,70}$. T-cell receptor (TCR) $\gamma$-chain rearrangements have been detected in a subset of peripheral NK cells in mice and provide a marker of their thymic origin ${ }^{71}$. This finding suggests that thymic NK cells and thymocytes share a common precursor (possibly the bipotent T- and NK-cell progenitor that has initiated TCR gene rearrangements) and use common signals (such as IL-7) to develop. Some thymic $\gamma \delta \mathrm{T}$ cells are $\mathrm{CD} 3{ }^{\text {low }} \mathrm{CD} 127^{+}$and express NK-cell markers, which makes them difficult to distinguish from thymic NK cells $^{72}$. Nevertheless, thymic NK cells are clearly detected in mice lacking recombination-activating gene 2 (Rag2), and thymic NK cells from wild-type and Rag $2^{-/}$mice have similar phenotypic and functional characteristics ${ }^{69}$. These results distinguish two subsets of mouse NK cells that rely on different sites of development, different transcriptional regulation and different soluble factors for their generation. Thymic and bone-marrow pathways of NK-cell development in mice generate NK-cell subsets with distinct phenotypic and functional characteristics.

NK cells can develop from human fetal thymic haematopoietic precursors ( $\mathrm{LIN}^{-} \mathrm{CD} 34^{\mathrm{hi}}$ cells) as revealed by in vitro culture or using murine FTOCs ${ }^{73-76}$. Later stages of thymocyte differentiation (that is, the acquisition of CD1a expression) correlate with a loss of NK-cell potential $^{77}$, suggesting that commitment to the T-cell lineage is incompatible with NK-cell development. In analogy to the GATA3-dependent thymic pathway described in mice, human thymic NK cells were uniformly shown to express CD127. Interestingly, analysis of CD127 and GATA3 expression in human peripheral blood NK-cell subsets showed that $\mathrm{CD} 16^{-} \mathrm{CD} 56^{\mathrm{hi}} \mathrm{NK}$ cells were $\mathrm{CD} 127^{+}$ and expressed GATA3, whereas $\mathrm{CD} 16^{+} \mathrm{CD} 56^{\text {low }} \mathrm{NK}$ cells were $\mathrm{CD} 127^{-}$and lacked GATA3 expression ${ }^{69,78}$. Finally, there are functional similarities between mouse $\mathrm{CD} 127^{+}$
NK cells and the human peripheral blood CD $56^{\text {hi }} \mathrm{NK}$ cells, as both populations are better producers of cytokines but are less cytotoxic than their CD127- counterparts.

Lymph nodes: an additional site for NK-cell development? The lymph node contains a small population of NK cells (about $0.5 \%$ ) that has escaped the interests of immunologists and NK-cell biologists for many years. However, the recent evidence for potential functional interactions between NK cells, DCs and $\mathrm{T}$ cells has sparked renewed interest in the biological roles of lymph-node NK cells (reviewed in REF. 79). Phenotypically, murine NK-cell populations in the lymph node have lower proportions of Ly $49^{+}$cells and are enriched in CD $11 b^{\text {low }}$ cells ${ }^{80}$. This may be due in part to the preferential migration of $\mathrm{CD}_{12} 7^{+}$thymic NK cells (which are CD11b ${ }^{\text {low }} \mathrm{Ly} 49^{-}$) to the lymph node ${ }^{69}$. Most NK cells gain access to lymph nodes by L-selectin-mediated passage through high endothelial vessels, and NK cells have been localized to the $\mathrm{T}$-cell zones and the medulla using antibodies specific for CD49b ${ }^{80,81}$, as well as using NKp46-GFP reporter mice $^{33}$ (J.P.D. and O. Mandelboim, unpublished observations). Unlike most other tissues, the lymph node contains both $\mathrm{CD} 127^{+}$and $\mathrm{CD} 127^{-}$NK-cell subsets ${ }^{69}$. An outstanding issue is whether thymic $\mathrm{CD} 127^{+} \mathrm{NK}$ cells have a distinct mechanism for localization within the lymph node and whether their tissue localization is associated with any unique biological function.

In humans, recent evidence suggests that the lymph node may provide a unique site for the development of CD16-CD56 ${ }^{\text {hi }} \mathrm{NK}$ cells ${ }^{27,41}$. Lymph-node-resident cells with the $\mathrm{LIN}^{-} \mathrm{CD} 34^{\text {low }} \mathrm{CD} 117^{\text {hi }} \alpha_{4} \beta_{7}$-integrin ${ }^{+}$phenotype can develop in a stepwise manner into CD56 ${ }^{\mathrm{hi}} \mathrm{NK}$ cells with classical NK-cell markers (CD122, CD11b, NKG2D and NKp46) ${ }^{41}$. One intermediate in this process included a subset of CD94-CD $117^{\text {hi }} \mathrm{CD} 161^{+}$ immature NK cells ${ }^{41}$; a similar population has been identified following culture of cord blood CD $34^{+} \mathrm{LIN}^{-}$ cells with IL-3, IL-7, IL-15, stem-cell factor (SCF) and FMS-like tyrosine kinase 3 ligand (FLT3L) ${ }^{82}$. Both in vitro derived and ex vivo sorted CD94-CD $117^{\text {hi }}$ cells could differentiate into $\mathrm{CD} 56^{+} \mathrm{CD} 94^{+} \mathrm{CD} 117^{\text {low }}$ cells in vitro ${ }^{41,82}$, indicating they have NK-cell precursor activity. Evidence suggests that these precursors derive from the bone marrow ${ }^{26,28,29}$, although it is possible that they have a thymic origin. It is not known whether lymph-node $\mathrm{LIN}^{-} \mathrm{CD} 34^{\text {low }} \mathrm{CD} 117^{\text {hi }} \alpha_{4} \beta_{7}$-integrin ${ }^{+}$cells can give rise to other cell types.

Interestingly, the ratio of $\mathrm{CD} 16^{+} \mathrm{CD} 56^{\text {low }}$ to $\mathrm{CD} 16^{-}$ CD56 ${ }^{\text {hi }} \mathrm{NK}$ cells in the lymph node contrasts that of the peripheral blood, with most lymph-node NK cells being CD $16^{-} \mathrm{CD} 56^{\text {hi }}$ (REF. 83). CD $16^{-} \mathrm{CD} 56^{\text {hi }} \mathrm{NK}$ cells express higher levels of CD62L, CCR7 and CXCR3, which may mediate their preferential recruitment to the lymph nodes ${ }^{84-86}$. Enhanced cytokine production by $\mathrm{CD} 16^{-} \mathrm{CD} 56^{\text {hi }} \mathrm{NK}$ cells following interactions with activated macrophages or DCs ${ }^{62,87}$ may have a role in priming $T$ helper $1\left(\mathrm{~T}_{H} 1\right)$-cell responses in the draining lymph nodes ${ }^{85,88}$. In addition to inducing CCR7 expression, IL-18 has been shown to reduce NK-cell 
cytotoxicity against activated DCs, promoting their production of IL-12 and IFN $\gamma$ (REF. 64), and thereby enhancing $\mathrm{T}_{\mathrm{H}} 1$-cell responses. Whether lymph-node-resident $\mathrm{CD} 127^{+} \mathrm{NK}$ cells in mice have an analogous role in T-cell differentiation is not known.

\section{Environmental 'shaping' of NK-cell diversity}

A large body of evidence supports the classification of phenotypically and functionally distinct NK-cell subsets in mice and humans. Recently, cell-surface markers (such as CD127 and TRAIL) have been used in combination with CD16 to provide a means to classify the main NK-cell subsets in both of these species (hepatic immature NK cells: TRAIL ${ }^{+}$; thymic NK cells: CD127; splenic and blood NK cells: $\mathrm{CD} 16^{+}$). It will be interesting to know whether these markers can be used to define NK-cell subsets in other species (including rats, cows or chimpanzees). An unambiguous identification of NK-cell subsets will provide a means to further characterize their specific functions and to define their roles in immune responses.

Several questions remain as to how these different NK-cell subsets arise, including the nature of the NK-cell precursors and the mechanisms that control the developmental pathway. Although NKPs have been identified in the bone marrow ${ }^{22}$, the presence of NKPs in the thymus and the developmental pathway that ultimately generates thymic NK cells remains to be elucidated. Although it is likely that the thymic microenvironment has a role in establishing the 'thymic' phenotype (CD127 expression and TCR $\gamma$-chain rearrangements), the intercellular and soluble signals that control this process are not defined, but could include Notch signalling, which is instrumental in specifying $\mathrm{CD}_{127^{+}}$early thymocyte progenitors ${ }^{89}$. A similar process of environmental conditioning of NK-cell sub-
Notch signalling

A signalling system

comprising highly conserved transmembrane receptors

that regulate cell-fate choice in the development of many cell lineages, and so are vital in the regulation of embryonic development.

\section{Antibody-dependent} cell-mediated cytotoxicity (ADCC). A cytotoxic mechanism by which an antibody-coated target cell is directly killed by a leukocyte that expresses Fc receptors, such as a natural killer (NK) cell, macrophage or neutrophil. A specific receptor for the Fc region of IgG, CD 16 (also known as FC $\gamma$ RIII), is expressed at the surface of most NK cells and on binding immunoglobulin, initiates a signalling cascade that results in the release of cytotoxic granules (containing perforin and granzyme B), which induce apoptosis of the antibodycoated cell. differentiation and present in the pregnant uterus. vascular growth and placental development ${ }^{116,120}$.
Although the genetic, phenotypic and functional evidence suggests that bone-marrow and thymic NK-cell developmental pathways are clearly distinct ${ }^{68}$, it remains possible that the thymic pathway is an extended version of a small developmental window that normally occurs in the bone marrow (for example, induced by Notch signals).

Another important issue is whether any NK-cell developmental intermediates found in different tissue sites are equivalent (or identical). This includes the nature of the thymus-derived cell that ultimately seeds the lymph node (FIG. 1). Circulation in the blood has already been described for several types of multipotent and more lineage-restricted haematopoietic precursors. Previous studies have also shown that the thymus can export early T-cell progenitors that can seed the gut and develop locally ${ }^{90}$. Whether thymus-derived early T-cell precursors provide the cellular substrate for lymphnode $\mathrm{CD} 127^{+} \mathrm{NK}$ cells should be assessed. The possibility that NKPs and immature NK cells could reach the circulation and home to other tissue sites would have several consequences. First, this would provide multiple opportunities for NK-cell development to occur if one developmental site were to be rendered non-functional. Second, developmental sites would not be fixed anatomically and 'neo-NK'-cell development would be possible at any site that provides the appropriate cellular and soluble factors.

Although there are plenty of data on the phenotype and function of NK-cell subsets, we still lack knowledge of their ontogenic relationships. For example, evidence suggests that CD $16^{-} \mathrm{CD} 56^{\text {hi }} \mathrm{NK}$ cells are precursors of $\mathrm{CD} 16^{+} \mathrm{CD} 56^{\text {low }} \mathrm{NK}$ cells. First, the proportion of $\mathrm{CD} 16^{-} \mathrm{CD} 56^{\text {hi }} \mathrm{NK}$ cells in the blood is increased in patients shortly after bone-marrow transplantation and declines over time in these patients, when the $\mathrm{CD} 16^{+} \mathrm{CD} 56^{\text {low }} \mathrm{NK}$-cell population becomes

\section{Box 3 | Uterine NK cells: a unique subset or NK cells shaped by the environment}

During pregnancy, the uterine decidua is dominated by the presence of CD16-CD56 hi natural killer (NK) cells ${ }^{116}$, known as uterine NK cells. Uterine NK cells are not identical to the CD $16^{-}$CD $56^{\text {hi }}$ NK cells found in the blood, as they express CD9, CD103 and a substantially greater proportion express one or more members of the KIR (killer-cell immunoglobulinlike receptor) family ${ }^{117}$. CD9, CD103 and KIR expression may be directly induced by transforming growth factor- $\beta$ (TGF $\beta$ ), produced by decidual stromal cells. The regulatory activity of TGF $\beta$ can also reduce CD16 expression on CD $166^{+}$CD $56^{\text {low }}$ NK cells ${ }^{117}$, thereby impairing NK-cell-mediated antibody-dependent cell-mediated cytotoxicity (ADCC). Finally, although uterine NK cells express similar levels of NKp46 (NK-cell protein 46), lymphocyte function-associated antigen 1 (LFA1) and NK group 2, member D (NKG2D) as peripheral blood NK cells, they express higher levels of NKp44 and fail to polarize perforin-containing granules required for target-cell lysis ${ }^{118}$. So, uterine NK cells seem to be phenotypically and functionally distinct from other human NK-cell subsets, which probably results from the unique cytokine environment

Uterine NK cells are thought to be recruited from the peripheral blood to the decidua; indeed, CD16-CD56 $6^{\text {hi }}$ NK cells from both the peripheral blood and the decidua preferentially express CXC-chemokine receptor 4 (CXCR4) and migrate towards soluble CXC-chemokine ligand 12 (CXCL12) found in the decidua, particularly on extravillous trophoblasts ${ }^{119}$. However, uterine NK cells could develop in situ, as the decidua contains lineage-CD $34^{+}$cells that differentiate into CD16-CD56 ${ }^{\text {hi }}$ cells in the presence of decidual-stroma-conditioned medium, interleukin-15 and stem-cell factor in vitro ${ }^{117}$. Irrespective of their origin, the function of uterine NK cells seems to be highly specialized, as the extraembryonic placenta is allogeneic yet is not rejected by the maternal NK cells. Extravillous trophoblasts invade the uterus and are involved in tissue remodelling, to ensure adequate maternal blood flow to the intervillous space for the fetus and placenta ${ }^{116}$. Decidual NK cells produce CXCL8 and CXCL10, which attract extravillous trophoblasts via CXCR1 and CXCR3, respectively. In addition, vascular endothelial growth factor (VEGF) and placental growth factor (PLGF) are produced at significantly higher levels by uterine NK cells compared with peripheral blood NK cells and could assist 
SCID mice

(Severe combined immunodeficiency mice)

Mice with a defect in DNA recombination that results in SCID. SCID mice lack B and $T$ cells and are incompetent in rejecting tissue grafts from allogeneic and xenogeneic sources.

Short hairpin RNA One of the two most common forms of short (usually 21-base-pairs long) double-stranded RNAs used for gene silencing. The other form is known as small interfering RNA (siRNA). more prominent ${ }^{91-93}$. Second, telomere length, which progressively diminishes with cell division and age, is significantly shorter in $\mathrm{CD} 16^{+} \mathrm{CD} 56^{\text {low }} \mathrm{NK}$ cells compared with $\mathrm{CD} 16^{-} \mathrm{CD} 56^{\mathrm{hi}} \mathrm{NK}$ cells from the same donor ${ }^{94}$. Third, CD16-CD56 ${ }^{\text {hi }}$ NK cells can differentiate into $\mathrm{CD} 16^{+} \mathrm{CD} 56^{\text {low }} \mathrm{NK}$ cells following transfer to alymphoid NOD/SCID mice (non-obese diabetic (NOD)/severe combined immunodeficiency (SCID) mice $)^{95}$. However, if CD $16^{-} \mathrm{CD} 56^{\text {hi }} \mathrm{NK}$ cells are analogous to mouse thymus-derived NK cells, there might be alternative explanations. For example, the same data are consistent with thymic NK cells arising early after bone-marrow grafting and having a shorter replicative history. Thymus transplantation in mice can be used to assess the precursor-product relationships of thymic NK cells with other defined NK-cell subsets. Comparison of NK-cell-mediated immune responses in wild-type mice, congenitally athymic nude mice and mice receiving thymus grafts should allow a better characterization of the biological role of thymic NK cells in vivo.

\section{Studying human NK-cell biology in mice}

Understanding the full complexity of human NK-cell development is hampered by our reliance on in vitro differentiation assays. Furthermore, ethical and technical considerations restrict access to fetal and newborn tissues, and adult samples are often limited to peripheral blood or diseased tissue samples. For over 20 years, immunodeficient mice have been used to create 'humanized' mouse models that are capable of maintaining transplanted, functional human cells, including lymphocytes ${ }^{96,97}$. Therefore, humanized mice should provide a valuable tool for studying human lymphocyte development and human immune-mediated diseases, and for vaccine development.

Recently, several groups have shown that mice deficient in T and B cells (using SCID or RAG-deficient mice) and NK cells (using mice deficient in $\gamma_{c}$ ) with a suitable genetic background (BALB/c or NOD) provide the appropriate conditions for human HSC development into T-cell and B-cell lineages ${ }^{98-100}$. The human immune system (HIS) mice also develop CD $16^{-} \mathrm{CD} 56^{\text {hi }}$ and $\mathrm{CD} 16^{+} \mathrm{CD} 56^{\text {low }}$ human NK-cell subsets that are present in the bone marrow, thymus, blood, liver and spleen, although their relative representation (of the total lymphocyte pool) is clearly less than that observed in humans $s^{99,101,102}$ (N.D.H. and J.P.D., unpublished observations). Administration of IL-15 in vivo ${ }^{101}$ increased the absolute numbers of human NK cells in HIS mice (N.D.H. and J.P.D., unpublished observations), suggesting an intimate relationship between IL-15 and NK-cell homeostasis in this model. Human NK cells generated in HIS mice were shown to express CD94, NKp46, CD62L, CD7, CD11b and KIR2DL2/KIR2DL3 ${ }^{101}$ (N.D.H. and J.P.D., unpublished observations). In addition, NK cells derived from HIS mice can lyse K562 tumour cells (an NK-cell-sensitive human leukaemia cell line) in vitro and in vivo, and produce IFN $\gamma$ after stimulation with IL-12 and IL-18 (REFS 101,102).
The ability to generate human NK-cell subsets in HIS mice and the ability of these mice to maintain human lymphocytes (for up to 6 months ${ }^{98}$ provides a unique opportunity to begin dissecting the process of human NK-cell development, albeit with some caveats. Given the observations in MHC-class-I-deficient mice and humans ${ }^{103,104}$, the efficiency of NK-cell differentiation in HIS mice may depend on adequate interaction with self MHC molecules during NK-cell education; which may be suboptimal given that both thymic and bone-marrow stromal cells are of mouse origin. Whether mouse cytokines and chemokines trigger the corresponding human receptors on developing NK cells is unclear, and inappropriate binding to or signalling in human NK cells could impair their development, survival, migration and function.

Still, the HIS mouse model offers a new and exciting opportunity to investigate human NK-cell development and function. It will be particularly interesting to investigate the role of human transcription factors, signalling proteins and receptors during human lymphocyte development by modulating the expression of these genes in $\mathrm{CD} 34^{+}$human stem cells before engraftment, as shown using viral expression of short hairpin RNA $^{99,105}$.

\section{Concluding remarks}

Diversification of functionally distinct NK-cell subsets seems to have been faithfully conserved during evolution, as shown by their existence in mice and humans. Evolutionary conservation is usually interpreted as a proof of 'usefulness' that translates to a survival advantage for the individual. What is the evidence that NK-cell diversification provides a biological advantage?

Although NK cells are characterized by an immediate response to a given stimulus (transformed cells or cytokines), not all NK cells respond equally, either quantitatively or qualitatively. This phenomenon is clearly demonstrated using studies of NK-cell function in vitro, and probably underestimates the heterogeneous nature of the response that occurs in vivo. It is likely that an even larger diversity of NK-cell responses (and subsets) is yet to be discovered. Developing new methods that allow for in situ analysis of NK-cell function coupled with multiparameter cellsurface phenotyping will help to address this issue. Nevertheless, the potential for a multitude of NK-cell subsets provides the organism with a diversified innate arsenal to protect itself. As such, the NK-cell population as a whole has the ability to respond rapidly to diverse assaults, relying on different NK-cell subsets to react quickly with their respective, specific stimulus and thereby rapidly clearing a diseased cell or sounding the alarm of the adaptive immune system. Certain NK-cell subsets are found at specific anatomical locations, which provide an increased probability to encounter their specific targets. Other locations may contain combinations of NK-cell subsets, generating a repertoire at the population level with the capacity to handle multiple types of danger. 
Trinchieri, G. Biology of natural killer cells. Adv. Immunol. 47, 187-376 (1989).

2. Ljunggren, H. G. $\&$ Malmberg, K. J. Prospects for the use of NK cells in immunotherapy of human cancer. Nature Rev. Immunol. (2007).

3. Kimura, M. Y. \& Nakayama, T. Differentiation of NK1 and NK2 Cells. Crit. Rev. Immunol. 25, 361-374 (2005).

4. Perussia, B. \& Loza, M. J. Linear “2-0-1" lymphocyte development: hypotheses on cellular bases for immunity. Trends Immunol. 24, 235-241 (2003).

5. Spits, H. \& Lanier, L. L. Natural killer or dendritic: what's in a name? Immunity 26, 11-16 (2007)

6. Vosshenrich, C. A., Samson-Villeger, S. I. \&

Di Santo, J. P. Distinguishing features of developing natural killer cells. Curr. Opin. Immunol. 17, 151-158 (2005).

7. Raulet, D. H., Vance, R. E. \& McMahon, C. W. Regulation of the natural killer cell receptor repertoire. Annu. Rev. Immunol. 19, 291-330 (2001).

8. Anfossi, N. et al. Human NK cell education by inhibitory receptors for MHC class I. Immunity 25, 331-342 (2006)

9. Cooley, S. et al. A subpopulation of human peripheral blood NK cells that lacks inhibitory receptors for self $\mathrm{MHC}$ is developmentally immature. Blood 110, 578-586 (2007).

10. Fernandez, N. C. et al. A subset of natural killer cells achieves self-tolerance without expressing inhibitor receptors specific for self-MHC molecules. Blood 105, 4416-4423 (2005).

11. Kim, S. et al. Licensing of natural killer cells by host major histocompatibility complex class I molecules. Nature 436, 709-713 (2005)

References 10 and 11 are the first papers to describe the influence of self MHC engagement for the generation of fully functional NK cells.

12. Yokoyama, W. M. \& Kim, S. How do natural killer cells find self to achieve tolerance? Immunity 24, 249-257 (2006).

13. Raulet, D. H. \& Vance, R. E. Self-tolerance of natural killer cells. Nature Rev. Immunol. 6, 520-531 (2006) References 12 and 13 are excellent recent reviews on the subject of NK-cell education.

14. Day, C. L. et al. PD-1 expression on HIV-specific $T$ cells is associated with T-cell exhaustion and disease progression. Nature 443, 350-354 (2006).

15. Kumar, V., Ben-Ezra, J., Bennett, M. \& Sonnenfeld, G. Natural killer cells in mice treated with ${ }^{89}$ strontium: normal target-binding cell numbers but inability to kill even after interferon administration. J. Immunol. 123, 1832-1838 (1979)

16. Seaman, W. E. et al. $\beta$-Estradiol reduces natural killer cells in mice. J. Immunol. 121, 2193-2198 (1978).

17. Colucci, F., Caligiuri, M. A. \& Di Santo, J. P. What does it take to make a natural killer? Nature Rev. Immunol. 3, 413-425 (2003).

18. Di Santo, J. P. Natural killer cell developmental pathways: a question of balance. Annu. Rev. Immunol. 24, 257-286 (2006)

19. Yokoyama, W. M., Kim, S. \& French, A. R. The dynamic life of natural killer cells. Annu. Rev. Immunol. 22, 405-429 (2004).

20. Hackett, J. Jr., Bennett, M. \& Kumar, V. Origin and differentiation of natural killer cells. I. Characteristics of a transplantable NK cell precursor. J. Immunol. 134, 3731-3738 (1985)

21. Perry, S. S., Welner, R. S., Kouro, T., Kincade, P. W. \& Sun, X. H. Primitive lymphoid progenitors in bone marrow with $\mathrm{T}$ lineage reconstituting potential. J. Immunol. 177, 2880-2887 (2006).

22. Rosmaraki, E. E. et al. Identification of committed NK cell progenitors in adult murine bone marrow. Eur. J. Immunol. 31, 1900-1909 (2001).

23. Vosshenrich, C. A. et al. Roles for common cytokine receptor $\gamma$-chain-dependent cytokines in the generation, differentiation, and maturation of NK cell precursors and peripheral NK cells in vivo. J. Immunol. 174, 1213-1221 (2005)

24. Miller, J. S., Verfaillie, C. ¿ McGlave, P. The generation of human natural killer cells from $\mathrm{CD} 34^{+} / \mathrm{DR}^{-}$primitive progenitors in long-term bone marrow culture. Blood 80, 2182-2187 (1992)

25. Lotzova, E., Savary, C. A. \& Champlin, R. E. Genesis of human oncolytic natural killer cells from primitive CD34+CD33- bone marrow progenitors. J. Immunol. 150, 5263-5269 (1993)

26. Galy, A., Travis, M., Cen, D. \& Chen, B. Human T, B, natural killer, and dendritic cells arise from a common bone marrow progenitor cell subset. Immunity 3, 459-473 (1995).
27. Freud, A. G. et al. A human $\mathrm{CD} 34^{+}$subset resides in lymph nodes and differentiates into CD56 $6^{\text {bright }}$ natura killer cells. Immunity 22, 295-304 (2005). Characterization of an NKP in the lymph nodes in humans that gives rise to a unique functional NK-cell subset.

28. Miller, J. S., Alley, K. A. \& McGlave, P. Differentiation of natural killer (NK) cells from human primitive marrow progenitors in a stroma-based long-term culture system: identification of a $\mathrm{CD} 34^{+} 7^{+}$ NK progenitor. Blood 83, 2594-2601 (1994).

29. Rossi, M. I. et al. B lymphopoiesis is active throughout human life, but there are developmental age-related changes. Blood 101, 576-584 (2003).

30. Cicuttini, F. M., Martin, M., Petrie, H. T. \& Boyd, A. W. A novel population of natural killer progenitor cells isolated from human umbilical cord blood. J. Immunol. 151, 29-37 (1993)

31. Moretta, A. et al. Activating receptors and coreceptors involved in human natural killer cell-mediated cytolysis. Annu. Rev. Immunol. 19, 197-223 (2001).

32. Gazit, R. et al. Lethal influenza infection in the absence of the natural killer cell receptor gene Ncr1. Nature Immunol. 7, 517-523 (2006)

33. Walzer, T. et al. Identification, activation, and selective in vivo ablation of mouse NK cells via NKp46. Proc. Natl Acad. Sci. USA 104, 3384-3389 (2007)

34. Kim, S. et al. In vivo developmental stages in murine natural killer cell maturation. Nature Immunol. 3, 523-528 (2002)

35. Dorfman, J. R. \& Raulet, D. H. Acquisition of Ly 49 receptor expression by developing natural killer cells. J. Exp. Med. 187, 609-618 (1998).

36. Lanier, L. L., Chang, C. \& Phillips, J. H. Human NKR-P1A. A disulfide-linked homodimer of the C-type lectin superfamily expressed by a subset of NK and T lymphocytes. J. Immunol. 153, 2417-2428 (1994).

37. Bennett, I. M. et al. Definition of a natural killer NKR-P1 A+/CD56-/CD 16- functionally immature human NK cell subset that differentiates in vitro in the presence of interleukin 12. J. Exp. Med. 184, 1845-1856 (1996).

38. Jaleco, A. C. et al. Fetal liver contains committed NK progenitors, but is not a site for development of CD34+ cells into T cells. J. Immunol. 159, 694-702 (1997)

39. Zamai, L. et al. Natural killer (NK) cell-mediated cytotoxicity: differential use of TRAIL and Fas ligand by immature and mature primary human NK cells. J. Exp. Med. 188, 2375-2380 (1998).

40. Takeda, K. et al. TRAIL identifies immature natura killer cells in newborn mice and adult mouse liver. Blood 105, 2082-2089 (2005).

41. Freud, A. G. et al. Evidence for discrete stages of human natural killer cell differentiation in vivo. J. Exp. Med. 203, 1033-1043 (2006)

42. Carlyle, J. R. et al. Missing self-recognition of Ocil/ Clr-b by inhibitory NKR-P1 natural killer cell receptors. Proc. Natl Acad. Sci. USA 101, 3527-3532 (2004).

43. lizuka, K., Naidenko, O. V., Plougastel, B. F. Fremont, D. H. \& Yokoyama, W. M. Genetically linked C-type lectin-related ligands for the NKRP1 family of natural killer cell receptors. Nature Immunol. 4, 801-807 (2003).

44. Bryceson, Y. T., March, M. E., Barber, D. F. Ljunggren, H. G. \& Long, E. O. Cytolytic granule polarization and degranulation controlled by different receptors in resting NK cells. J. Exp. Med. 202, 1001-1012 (2005)

45. Hayakawa, Y. \& Smyth, M. J. CD27 dissects mature NK cells into two subsets with distinct responsiveness and migratory capacity. J. Immunol. 176, 1517-1524 (2006).

An interesting paper describing functional subsets of mature NK cells in mice that differ in their expression of CD27.

46. Huntington, N. D. et al. NK cell maturation and peripheral homeostasis is associated with KLRG1 up-regulation. J. Immunol. 178, 4764-4770 (2007).

47. Robbins, S. H. et al. Cutting edge: inhibitory functions of the killer cell lectin-like receptor $\mathrm{G} 1$ molecule during the activation of mouse NK cells. J. Immunol. 168, 2585-2589 (2002).

48. Whiteside, T. L. \& Herberman, R. B. Role of human natural killer cells in health and disease. Clin. Diagn. Lab. Immunol. 1, 125-133 (1994).

49. Ferlazzo, G. et al. The abundant NK cells in human secondary lymphoid tissues require activation to express killer cell lg-like receptors and become cytolytic. J. Immunol. 172, 1455-1462 (2004).
50 Lanier L. L., Le, A. M., Phillips, J. H., Warner, N. L. \& Babcock, G. F. Subpopulations of human natural killer cells defined by expression of the Leu-7 (HNK-1) and Leu-11 (NK-15) antigens. J. Immunol. 131, 1789-1796 (1983).

51. Freud, A. G. \& Caligiuri, M. A. Human natural killer cell development. Immunol. Rev. 214, 56-72 (2006).

52. Farag, S. S. ¿ Caligiuri, M. A. Human natural killer cell development and biology. Blood Rev. 20, 123-137 (2006).

53. Lanier, L. L., Le, A. M., Civin, C. I., Loken, M. R. \& Phillips, J. H. The relationship of CD 16 (Leu-11) and Leu-19 (NKH-1) antigen expression on human peripheral blood NK cells and cytotoxic T lymphocytes. J. Immunol. 136, 4480-4486 (1986).

The first report of differential expression of CD16 by human NK cells and the functional characterization of NK-cell subsets.

54. Caligiuri, M. A. et al. Functional consequences of interleukin 2 receptor expression on resting human lymphocytes. Identification of a novel natural killer cell subset with high affinity receptors. J. Exp. Med. 171, 1509-1526 (1990)

55. Campbell, J. J. et al. Unique subpopulations of CD56+ NK and NK-T peripheral blood lymphocytes identified by chemokine receptor expression repertoire. J. Immunol. 166, 6477-6482 (2001).

56. Matos, M. E. et al. Expression of a functional c-kit receptor on a subset of natural killer cells. J. Exp. Med. 178, 1079-1084 (1993)

57. Voss, S. D., Daley, J., Ritz, J. \& Robertson, M. J. Participation of the CD94 receptor complex in costimulation of human natural killer cells. J. Immunol. 160, 1618-1626 (1998).

58. André, P. et al. Modification of P-selectin glycoprotein ligand-1 with a natural killer cellrestricted sulfated lactosamine creates an alternate ligand for L-selectin. Proc. Natl Acad. Sci. USA 97, 3400-3405 (2000)

59. Frey, M. et al. Differential expression and function of L-selectin on CD56 bright and CD56 $6^{\text {dim }}$ natural killer cell subsets. J. Immunol. 161, 400-408 (1998).

60. Nagler, A., Lanier, L. L. \& Phillips, J. H. Constitutive expression of high affinity interleukin 2 receptors on human CD16-natural killer cells in vivo. J. Exp. Med. 171, 1527-1533 (1990)

61. Jacobs, R. et al. CD56 $6^{\text {bright }}$ cells differ in their KIR repertoire and cytotoxic features from CD56 dim NK cells. Eur. J. Immunol. 31, 3121-3127 (2001).

62. Cooper, M. A. et al. Human natural killer cells: a unique innate immunoregulatory role for the CD56 bright subset. Blood 97, 3146-3151 (2001)

63. Nagler, A., Lanier, L. L., Cwirla, S. \& Phillips, J. H. Comparative studies of human FcRIII-positive and negative natural killer cells. J. Immunol. 143, 31833191 (1989)

64. Mailliard, R. B. et al. IL-18-induced CD83+CCR7 NK helper cells. J. Exp. Med. 202, 941-953 (2005).

65. Loza, M. J. \& Perussia, B. The IL-12 signature: NK cell terminal CD56 $6^{\text {high }}$ stage and effector functions. J. Immunol. 172, 88-96 (2004).

66. Robertson, M. J. et al. Response of human natural killer (NK) cells to NK cell stimulatory factor (NKSF): cytolytic activity and proliferation of NK cells are differentially regulated by NKSF. J. Exp. Med. 175, 779-788 (1992).

67. Ellis, T. M. \& Fisher, R. I. Functional heterogeneity of Leu 19 "bright" + and Leu 19"dim"+ lymphokine-activated killer cells. J. Immunol. 142, 2949-2954 (1989).

68. Di Santo, J. P. \& Vosshenrich, C. A. Bone marrow versus thymic pathways of natural killer cell development. Immunol. Rev. 214, 35-46 (2006).

69. Vosshenrich, C. A. et al. A thymic pathway of mouse natural killer cell development characterized by expression of GATA-3 and CD127. Nature Immunol. 7, 1217-1224 (2006).

This paper describes a thymic pathway of NK-cell development in mice characterized by CD 127 expression that generates NK-cell subsets with functional properties similar to human CD56+ NK-cell subsets.

70. Vosshenrich, C. A. et al. Common cytokine receptor $\gamma$ chain $\left(\gamma_{\mathrm{c}}\right)$-deficient B cells persist in T cell-deficient $\gamma^{-}$mice and respond to a T-independent antigen. Eur. J. Immunol. 30, 1614-1622 (2000).

71. Veinotte, L. L., Greenwood, C. P., Mohammadi, N. Parachoniak, C. A. \& Takei, F. Expression of rearranged $\mathrm{TCR} \gamma$ genes in natural killer cells suggests a minor thymus-dependent pathway of lineage commitment. Blood 107, 2673-2679 (2006). 
72. Stewart, C. A. et al. Germ-line and rearranged Tcrd transcription distinguish bona fide NK cells and NK-like $\gamma \delta \mathrm{T}$ cells. Eur. J. Immunol. 37, 1442-1452 (2007)

73. Res, P. et al. CD $34{ }^{+} \mathrm{CD} 38^{\text {dim }}$ cells in the human thymus can differentiate into $\mathrm{T}$, natural killer, and dendritic cells but are distinct from pluripotent stem cells. Blood 87, 5196-5206 (1996).

74. Phillips, J. H. \& Lanier, L. L. Acquisition of non-MHC restricted cytotoxic function by IL 2 activated thymocytes with an "immature" antigenic phenotype. J. Immunol. 139, 683-687 (1987).

75. Sánchez, M. J., Muench, M. O., Roncarolo, M. G., Lanier, L. L. \& Phillips, J. H. Identification of a common T/natural killer cell progenitor in human fetal thymus. J. Exp. Med. 180, 569-576 (1994)

76. Sato, T., Laver, J. H., Aiba, Y. \& Ogawa, M. NK cell colony formation from human fetal thymocytes. Exp. Hematol. 27, 726-733 (1999).

77. Spits, H. et al. Early stages in the development of human T, natural killer and thymic dendritic cells. Immunol. Rev. 165, 75-86 (1998).

78. Hanna, J. et al. Novel insights on human NK cells' immunological modalities revealed by gene expression profiling. J. Immunol. 173, 6547-6563 (2004).

79. Moretta, L. et al. Effector and regulatory events during natural killer-dendritic cell interactions. Immunol. Rev. 214, 219-228 (2006)

80. Chen, S., Kawashima, H., Lowe, J. B., Lanier, L. L. \& Fukuda, M. Suppression of tumor formation in lymph nodes by L-selectin-mediated natural killer cell recruitment. J. Exp. Med. 202, 1679-1689 (2005).

81. Bajenoff, M. et al. Natural killer cell behavior in lymph nodes revealed by static and real-time imaging. J. Exp. Med. 203, 619-631 (2006).

82. Grzywacz, B. et al. Coordinated acquisition of inhibitory and activating receptors and functional properties by developing human natural killer cells. Blood 108, 3824-3833 (2006).

83. Fehniger, T. A. et al. CD56 bright natural killer cells are present in human lymph nodes and are activated by $T$ cell-derived IL-2: a potential new link between adaptive and innate immunity. Blood 101, 3052-3057 (2003).

84. Gallatin, W. M. Weissman, I. L. \& Butcher, E. C. A cell-surface molecule involved in organ-specific homing of lymphocytes. Nature 304, 30-34 (1983).

85. Martín-Fontecha, A. et al. Induced recruitment of NK cells to lymph nodes provides IFN- $\gamma$ for $T_{1}$ priming. Nature Immunol. 5, 1260-1265 (2004).

86. Kim, C. H. et al. CCR7 ligands, SLC/6Ckine/Exodus2/ TCA4 and CK $\beta-11 /$ MIP-3 $\beta / E L C$, are chemoattractants for $\mathrm{CD} 56^{+} \mathrm{CD}_{16} 6^{-} \mathrm{NK}$ cells and late stage lymphoid progenitors. Cell. Immunol. 193, 226-235 (1999).

87. Cooper, M. A., Fehniger, T. A. \& Caligiuri, M. A. The biology of human natural killer-cell subsets. Trends Immunol. 22, 633-640 (2001). A classic review on the two human NK-cell subsets characterized by differential CD56 expression.

88. Morandi, B., Bougras, G., Muller, W. A., Ferlazzo, G. \& Munz, C. NK cells of human secondary lymphoid tissues enhance T cell polarization via IFN- $\gamma$ secretion. Eur. J. Immunol. 36, 2394-2400 (2006).

89 García-Peydró, M. de Yébenes, V. G \& Toribio, M. L. Notch 1 and IL-7 receptor interplay maintains proliferation of human thymic progenitors while suppressing non-T cell fates. J. Immunol. 177, 3711-3720 (2006)

90. Lambolez, F. et al. The thymus exports long-lived fully committed T cell precursors that can colonize primary lymphoid organs. Nature Immunol. 7, 76-82 (2006).
91. Gottschalk, L R Bray, R A Kaizer H \& Gebel, H M Two populations of CD56 (Leu-19)+/CD 16 $6^{+}$cells in bone marrow transplant recipients. Bone Marrow Transplant. 5, 259-264 (1990)

92. Jacobs, R. et al. CD16-CD56 ${ }^{+}$natural killer cells after bone marrow transplantation. Blood 79, 3239-3244 (1992).

93. Chklovskaia, E. et al. Reconstitution of dendritic and natural killer-cell subsets after allogeneic stem cell transplantation: effects of endogenous flt3 ligand. Blood 103, 3860-3868 (2004)

94. Ouyang, O., Baerlocher, G., Vulto, I. \& Lansdorp, P. M. Telomere length in human natural killer cell subsets. Ann. NY Acad. Sci. 1106, 240-252(2007).

95. Chan, A. et al. CD56 bright human NK cells differentiate into CD56 dim cells: role of contact with peripheral fibroblasts. J. Immunol. 179, 89-94 (2007).

96. Legrand, N., Weijer, K. \& Spits, H. Experimental models to study development and function of the human immune system in vivo. J. Immunol. 176, 2053-2058 (2006).

97. Shultz, L. D., Ishikawa, F. \& Greiner, D. L. Humanized mice in translational biomedical research. Nature Rev. Immunol. 7, 118-130 (2007)

98. Traggiai, E. et al. Development of a human adaptive immune system in cord blood cell-transplanted mice. Science 304, 104-107 (2004).

99. Gimeno, R. et al. Monitoring the effect of gene silencing by RNA interference in human CD34 cells injected into newborn RAG2 $2^{---} \gamma \mathrm{c}^{-/-}$mice: functional inactivation of p53 in developing T cells. Blood 104, 3886-3893 (2004). References 98 and 99 describe novel humanized mice that develop a complete immune system including B, T and NK cells.

100. Legrand, N. et al. Transient accumulation of human mature thymocytes and regulatory T cells with CD28 superagonist in "human immune system" $\operatorname{Rag} 2^{-/-} \gamma_{c}^{-1}$ mice. Blood 108, 238-245 (2006).

101. Kalberer, C. P., Siegler, U. \& Wodnar-Filipowicz, A. Human NK cell development in NOD/SCID mice receiving grafts of cord blood $\mathrm{CD} 34^{+}$cells. Blood 102, 127-135 (2003)

102. Hiramatsu, H. et al. Complete reconstitution of human lymphocytes from cord blood CD34+ cells using the NOD/SCID $/ \gamma_{c}^{\text {null }}$ mice model. Blood $102,873-880$ (2003)

103. Liao, N. S., Bix, M., Zijlstra, M., Jaenisch, R. \& Raulet, D. MHC class I deficiency: susceptibility to natural killer (NK) cells and impaired NK activity. Science 253, 199-202 (1991).

104. Furukawa, H. et al. Tolerance of NK and LAK activity for HLA class I-deficient targets in a TAP1-deficient patient (bare lymphocyte syndrome type I). Hum. Immunol 60, 32-40 (1999).

105. Schotte, R., Nagasawa, M., Weijer, K., Spits, H. \& Blom, B. The ETS transcription factor Spi-B is required for human plasmacytoid dendritic cell development. J. Exp. Med. 200, 1503-1509 (2004).

106. Smyth, M. J. et al. Tumor necrosis factor-related apoptosis-inducing ligand (TRAIL) contributes to interferon $\gamma$-dependent natural killer cell protection from tumor metastasis. J. Exp. Med. 193, 661-670 (2001).

107. Hata, K. et al. Isolation, phenotyping, and functional analysis of lymphocytes from human liver. Clin. Immunol. Immunopathol. 56, 401-419 (1990).

108. Norris, S. et al. Resident human hepatic lymphocytes are phenotypically different from circulating lymphocytes. J. Hepatol. 28, 84-90 (1998).

109. Doherty, D. G. \& O'Farrelly, C. Innate and adaptive lymphoid cells in the human liver. Immunol. Rev. 174, 5-20 (2000)
110. Dunn, C. et al. Cytokines induced during chronic hepatitis B virus infection promote a pathway for NK cell-mediated liver damage. J. Exp. Med. 204 667-680 (2007)

111. Taieb, J. et al. A novel dendritic cell subset involved in tumor immunosurveillance. Nature Med. 12, 214-219 (2006)

112. Chan, C. W. et al. Interferon-producing killer dendritic cells provide a link between innate and adaptive immunity. Nature Med. 12, 207-213 (2006).

113. DiSanto, J. P., Muller, W., Guy-Grand, D., Fischer, A. \& Rajewsky, K. Lymphoid development in mice with a targeted deletion of the interleukin 2 receptor $\gamma$ chain. Proc. Natl Acad. Sci. USA 92, 377-381 (1995).

114. Phillips, J. H., Le, A. M. \& Lanier, L. L. Natural killer cells activated in a human mixed lymphocyte response culture identified by expression of Leu-11 and class II histocompatibility antigens. J. Exp. Med. 159, 993-1008 (1984)

115. Hanna, J. et al. Novel APC-like properties of human NK cells directly regulate T cell activation. J. Clin. Invest. 114, 1612-1623 (2004).

116. Moffett-King, A. Natural killer cells and pregnancy. Nature Rev. Immunol. 2, 656-663 (2002).

117. Keskin, D. B. et al. TGF $\beta$ promotes conversion of CD $16^{+}$peripheral blood NK cells into CD 16 ${ }^{-}$NK cells with similarities to decidual NK cells. Proc. Natl Acad. Sci. USA 104, 3378-3383 (2007)

118. Kopcow, H. D. et al. Human decidual NK cells form immature activating synapses and are not cytotoxic. Proc. Natl Acad. Sci. USA 102, 15563-15568 (2005).

119. Hanna, J. et al. CXCL12 expression by invasive trophoblasts induces the specific migration of CD16human natural killer cells. Blood 102, 1569-1577 (2003).

120. Hanna, J. et al. Decidual NK cells regulate key developmental processes at the human fetal-materna interface. Nature Med. 12, 1065-1074 (2006).

121. Vremec, D. et al. Production of interferons by dendritic cells, plasmacytoid cells, natural killer cells, and interferon-producing killer dendritic cells. Blood 109, 1165-1173 (2007).

122. Welner, R. S. et al. Interferon-producing killer dendritic cells (IKDC) arise via a unique differentiation pathway from primitive c-kit ${ }^{\text {Hi }} \mathrm{CD} 62 \mathrm{~L}^{+}$lymphoid progenitors. Blood 109, 4825-4831 (2007).

\section{Acknowledgements}

This work is supported by grants from Institut Pasteur, Inserm Ligue National Contre le Cancer, and a Grand Challenges in Global Health grant from the Bill $\&$ Melinda Gates Foundation. We thank E. Corcuff, N. Legrand, O. Mandelboim, H. Spits and K. Weijer for their excellent collaboration. We apologize to those colleagues whose work has not been cited due to space constraints.

Competing interests statement

The authors declare no competing financial interests.

DATABASES

Entrez Gene:

http://www.ncbi.nlm.nih.gov/entrez/query.fcgi?db=gene

$\underline{\mathrm{CD} 11 \mathrm{~b}}|\underline{\mathrm{CD} 16}| \underline{\mathrm{CD} 27}|\underline{\mathrm{CD} 49 \mathrm{~b}}| \mathrm{CD} 56|\underline{\mathrm{CD} 94}| \underline{\mathrm{CD} 117} \mid$

NKRP1A INKRP1C ITRAIL

FURTHER INFORMATION

James P. Di Santo's homepage:

http://www.pasteur.fr/recherche/RAR/RAR2006/Cytotbnk.

htm

ALL LINKS ARE ACTIVE IN THE ONLINE PDF 